\title{
A avaliação institucional como instrumento de gestão e consolidação do projeto pedagógico institucional na educação superior.
}

\section{Institutional assessment as an instrument for management and consolidation of the institutional pedagogical project in higher education.}

\section{Clarice Pires}

Faculdade Social da Bahia

E-mail: clapires@icloud.com

Daniela Adami Goes De Araujo

Faculdade Social da Bahia

E-mail: professora.daniela.adami@gmail.com

\section{RESUMO}

O presente artigo relata evidências a partir dos processos de avaliações externas que demonstram o quanto a avaliação institucional subsidia a gestão e a consolidação dos Projetos Pedagógicos Institucionais nas IES. Aborda as possibilidades de articulação entre a autoavaliação e o planejamento institucional, mediante processos de regulação e/ou emancipação. Trata-se de um relato de experiência, fundamentado nas avaliações in loco vivenciadas pelas pesquisadoras como avaliadoras ad hoc do INEP-MEC. O estudo traz breves considerações acerca das percepções das avaliadoras sobre a concepção e prática da avaliação institucional, o que implica afirmar que neste processo evidencia-se ainda práticas mais voltadas para a regulação do que a emancipação.

Palavras chave: Autoavaliação; Projeto Pedagógico Institucional; Planejamento; Regulação; Emancipação.

\section{ABSTRACT}

This article reports evidence from external evaluation processes that demonstrate how institutional evaluation subsidizes the management and consolidation of Institutional Pedagogical Projects in HEls. It approaches the possibilities of articulation between self-assessment and institutional planning, through processes of regulation and/or emancipation. This is an experience report, based on the onsite evaluations experienced by the researchers as ad hoc evaluators for INEPMEC. The study brings brief considerations about the perceptions of the evaluators on the conception and practice of institutional assessment, which implies affirming that in this process it is still evident practices more focused on regulation than emancipation.

Key words: Self-assessment; Institutional Pedagogical Project; Planning; Regulation; Emancipation. 


\section{INTRODUÇÃO}

A avaliação institucional é uma modalidade avaliativa que tem por finalidade a melhoria contínua de todas as atividades acadêmico-administrativas ofertadas pelas Instituições de ensino superior.

Com a implantação do SINAES, a partir da lei 10.861/2004, a avaliação tornou-se obrigatória e ocorre em dois momentos que, embora distintos, se complementam: o primeiro é a autoavaliação, na qual a própria IES deve avaliar suas práticas tanto em termos institucionais como em cada um de seus cursos ofertados e o segundo momento são as avaliações externas para fins de credenciamento e recredenciamento das IES e autorização, reconhecimento e renovação de reconhecimento de cursos, tanto na modalidade presencial quanto EAD.

Neste contexto, as autoras para a elaboração deste artigo escolheram como tema a avaliação institucional como instrumento de gestão e consolidação do projeto pedagógico institucional na educação superior.

Para a abordagem do tema acima proposto, optou-se pela metodologia do relato de experiência das avaliadoras, cujas evidências a partir dos processos de avaliações externas, demonstram o quanto a avaliação institucional subsidia a gestão e a consolidação dos projetos pedagógicos institucionais nas IES.

Inicialmente o artigo trata do referencial teórico sobre a política de avaliação da educação superior em uma perspectiva de regulação e/ou emancipação. $\mathrm{Na}$ sequencia, apresenta a metodologia e respectivos procedimentos adotados para a analise das evidencias coletadas, assim como, as percepções das avaliadoras a partir de reflexões teórico-práticas.

\section{A POLÍTICA DE AVALIAÇÃO DA EDUCAÇÃO SUPERIOR - REGULAÇÃO OU EMANCIPAÇÃO. \\ Dentro do contexto de reforma e de mudanças, vimos que o Projeto} Pedagógico Institucional - PPI se apresenta como uma nova forma de intervenção que busca atender às expectativas e às demandas sociais, diante das dificuldades e avanços da instituição, objetivando, assim, o diálogo crítico e significativo com o seu entorno, na produção e disseminação de novos conhecimentos.

Tal amplitude impõe às instituições o reconhecimento dos aspectos internos e externos que se encontram imbricados e fazem parte da dinâmica institucional, isto é, a atenção sistemática, estruturada e contínua direcionada à qualidade, em termos de ação e inovação.

$\mathrm{Na}$ perspectiva de um projeto pedagógico institucional críticoemancipatório, é importante considerar que a qualidade se coloca como um processo compartilhado, negociado, em termos de exigências e expectativas, com a comunidade envolvida.

[...] A comunidade pode tornar-se "o campo privilegiado do conhecimento- emancipação" se este for concebido como trajectória que leva o indivíduo de um estado de ignorância a um estado de saber que se pode designar por solidariedade (um conhecimento que "progride do 
colonialismo para a solidariedade"); e se a solidariedade for "o processo, sempre inacabado, de capacitação para a reciprocidade através da construção de sujeitos que a exercitem" ou "sujeitos capazes de reciprocidade". (AFONSO, 2000, p.123)

Esta qualidade se traduz na missão, nas metas e objetivos institucionais, não podendo, desta forma, ser estabelecida a priori e nem de forma universal. $A$ qualidade no projeto deverá estar intimamente associada à responsabilidade social, isto é, a instituição deve expressar sua preocupação com o tipo de formação que está promovendo, buscando saber em que medida atende às necessidades da comunidade.

Nesta direção, a avaliação se coloca como um instrumento fundamental cuja responsabilidade ética e política é a de possibilitar a participação ativa e democrática da comunidade acadêmica na vida pública. Ela é muito mais do que uma mera prestação de contas, regulação social e/ou controle (ABRAMOWICZ e LARA, 2010).

Como instrumento de gestão para a implementação de um projeto pedagógico institucional, a avaliação implica um processo sistemático, cuja atividade estruturada deverá permitir o julgamento da qualidade institucional relativa à sua responsabilidade social e às suas metas e ações. Esta responsabilidade diz respeito ao posicionamento da universidade em favor da construção do conhecimento solidário e emancipador.

Significa afirmar que a avaliação como estratégia de gestão para a qualidade social deverá ser desenvolvida numa perspectiva de totalidade, articulada a um projeto mais amplo de sociedade. E nesta direção, segundo Afonso (2000), as funções da avaliação precisam ser compreendidas no contexto das mudanças educacionais, mudanças econômicas e políticas mais amplas.

Nas organizações, a avaliação é quase sempre um instrumento fundamental em termos de gestão. Particularmente importante na estruturação das relações de trabalho [...] a avaliação é também um instrumento importante de controle e de legitimação organizacional [...] As funções simbólicas, de controle social e de legitimação política, apesar de menos referidas, são funções que têm um maior interesse analítico quando se problematiza a avaliação para além dos limites mais restritos do espaço pedagógico (AFONSO, 2000, p. 18-19).

Cabe refletir criticamente o surgimento da avaliação no contexto brasileiro que, como um instrumento de gestão desde a sua implementação na década de 
90, acabou por assumir uma função muito mais regulatória na seleção e gestão produtivista do sistema educativo. Assim, como em outros países, a criação de um mercado educacional fez com que a avaliação tivesse um papel fundamental como um mecanismo importante na definição de escolhas e tomada de decisão.

Dentre os princípios assumidos pela política de diversificação e diferenciação, a avaliação da educação superior teve sua importância ressaltada, pois tinha por função permitir a expansão e o acesso ao ensino superior, sem queda de qualidade, no entanto, "[...] ganhou forte destaque como forma de controle e de definição de políticas que estimulem a expansão competitiva do ensino superior" (CATANI e OLIVEIRA, 2000, p. 69).

O modelo de avaliação adotado na década de 90 contemplou mecanismos externos e internos, sendo que o primeiro (o Exame Nacional de Cursos - Provão) trouxe, para este contexto, indicadores universais e quantitativos para todas as instituições, objetivando a comparação de desempenhos entre elas. Estes indicadores foram considerados de prioridade nacional e eram marcados pela homogeneização de critérios e pela centralização administrativa.

Como consequência, no plano prático, os impactos desta intervenção política desestimularam o trabalho com a diversidade no cotidiano das instituições, reforçando a ideia de que o sistema educacional deveria ser competitivo, nem que para isto fosse necessário instituir um sistema de incentivos e punições.

A publicação de rankings das universidades sob a ameaça de fechamento de cursos acabou reforçando esta realidade que, segundo Pacheco (2000), busca a diversificação, fomentando sua justificativa na qualidade do sistema educativo que é avaliada por indicadores resultantes do desempenho acadêmico.

[...] a política curricular, que consagra a diversificação como pré-requisito para a desigualdade, é fomentada da pretensa qualidade do sistema educativo, avaliada pelos indicadores dos resultados obtidos pelos alunos nos testes nacionais, incluindo os exames de homogeneização a nível nacional e os teste externos de avaliação criterial, e do ranking das escolas em termos de classificação nacional dos alunos (PACHECO, 2000, p.133).

Como podemos observar, temos aí uma política curricular paradoxalmente diversificadora e homogeneizadora, pois ao mesmo tempo em que buscou liberalizar o ensino superior como forma de flexibilizar os processos, objetivando alcançar a qualidade, dirigiu o julgamento de valor para a excelência dos 
resultados e não para os processos.

Ressaltamos também a interferência deste mecanismo de avaliação no exercício da docência e nos cursos de graduação. Na opinião de Cunha (2004), se a avaliação trouxe contribuições positivas, estas foram percebidas no contexto curricular dos cursos de graduação, quando os docentes passaram a discutir suas limitações e sua prática docente com maior freqüência.

Os impactos foram mais negativos do que positivos, pois o imaginário coletivo de autoavaliação construído neste meio fez com que ocorressem muitos equívocos neste cotidiano. A cultura do sistema regulatório acabou por legitimar, no imaginário social, a ideia de que os conceitos alcançados pelos cursos eram resultados de um desempenho satisfatório ou não. Muitos cursos passaram a assumir esta avaliação e isto mexeu significativamente com a subjetividade das pessoas.

A cultura da avaliação de desempenho encontrou campo fértil na academia, com algumas instituições desenvolvendo ações voltadas para um processo regulatório. Usamos como exemplo o movimento de alguns cursos na preparação de rituais, com aulas de reforço, confecção de materiais, premiações, entre outras estratégias que objetivavam preparar a comunidade acadêmica para obter um resultado favorável no ENADE do MEC.

Como um processo externo, de responsabilidade do poder público, este dispositivo de avaliação teve sua ênfase muito mais voltada para a dimensão regulatória (concepção classificatória). Procurou atender e dar respostas ao mercado, aumentando cada vez mais a competitividade.

Já o segundo modelo de avaliação, o PAIUB, esteve muito mais próximo de um processo contínuo de aperfeiçoamento do desempenho institucional, pois seus resultados puderam ser utilizados como ferramenta no redimensionamento e planejamento das instituições. Entendemos que, apesar de tal modalidade, regulamentada como política de avaliação nacional, não ter sido implementada com a mesma intensidade e impacto da avaliação externa, caminhou de modo evolutivo dentro do sistema, adotando uma perspectiva emancipatória, o que de certa forma contribuiu para gerar uma nova proposta de avaliação da educação superior brasileira.

Mediante um projeto pedagógico institucional que se deseja emancipatório, 
a grande questão que tem permeado as discussões e críticas nesta direção é: Neste processo, somos sujeitos ou objetos da avaliação? Sabemos que todo processo de avaliação carrega em si elementos de emancipação e regulação, no entanto, os processos de avaliação são culturais e, neste sentido, devem respeitar a realidade e as práticas sociais. Muito pouco adianta mudar o processo avaliativo se as mudanças não se traduzirem em melhorias para a instituição e para as pessoas com ela envolvidas.

No caso da avaliação institucional, ela deixou de ser uma atividade opcional no processo educativo e se transformou em componente curricular necessário, pois tem levado as instituições a questionarem se, em seu projeto pedagógico institucional, os objetivos e as metas estão sendo alcançados, e a medirem seu desempenho a partir de um padrão constituído coletivamente. Importa destacar que assumir a avaliação como cultura é assumir uma concepção de conhecimento enquanto processo e não como produto.

Por isso, a avaliação deve ser permanente e instalar-se como cultura, como ação organizada e programática que pense constantemente e de modo integrado a universidade e contribua para o cumprimento mais eficaz e com maior qualidade de suas funções e de seus compromissos fundamentais (SOBRINHO, 2000, p. 104).

A atual proposta do Sistema Nacional de Avaliação - SINAES parece caminhar nesta direção, sendo que os princípios que a fundamentam trazem como referenciais a responsabilidade social vinculada à qualidade da educação superior; o reconhecimento da diversidade do sistema; o respeito à identidade, à missão e à história das instituições; a globalidade, isto é, a compreensão de que a instituição deve ser avaliada a partir de um conjunto significativo de indicadores de qualidade, vistos em sua relação orgânica e não de forma isolada; e a continuidade do processo avaliativo.

\section{METOdOLOGIA}

Para a construção deste artigo, a metodologia utilizada pelas autoras foi o relato de experiências. O relato deve trazer considerações significativas a partir das vivências dos pesquisadores para o campo estudado, estabelecendo ponderações e reflexões embasadas em um suporte teórico.

A autora, Profa. Clarice Pires é doutora em Educação na área de Currículo 
pela Pontifícia Universidade Católica de São Paulo e avaliadora institucional para cursos presenciais e EAD do INEP - MEC. Atualmente é Coordenadora Acadêmica da Faculdade Social da Bahia - FSBA. A segunda autora, Profa. Daniela Adami Goes de Araujo é mestra e possui MBA em Gestão Executiva de IES. Atua como avaliadora de Cursos pelo INEP-MEC. No momento, é Coordenadora da Comissão Própria de Avaliação - CPA da Faculdade Social da Bahia.

Para a coleta e análise dos resultados foram utilizadas perguntas, normalmente aplicadas nas entrevistas in loco nos diversos segmentos da comunidade acadêmica, conforme quadro abaixo:

Quadro 1 - Perguntas realizadas com os diversos segmentos da comunidade acadêmica nas avaliações in loco.

\begin{tabular}{|c|l|}
\hline SEGMENTO DA COMUNIDADE & \multicolumn{1}{c|}{ PERGUNTAS } \\
\hline $\begin{array}{c}\text { Coordenadores acadêmicos e gestores } \\
\text { administrativos. }\end{array}$ & $\begin{array}{l}\text { De que forma são operacionalizados e tratados } \\
\text { os resultados do relatório de Autoavaliação } \\
\text { emitidos pela CPA? }\end{array}$ \\
\hline Docentes e Discentes & $\begin{array}{l}\text { Os docentes e discentes acessam às } \\
\text { informações da autoavaliação e participam de } \\
\text { debates e encontros para discussão dos } \\
\text { resultados? }\end{array}$ \\
\hline NDE - Núcleo Docente Estruturante & $\begin{array}{l}\text { Qual a dinâmica de operacionalização das da } \\
\text { decisões da CPA e do NDE - Núcleo Docente } \\
\text { Estruturante no cotidiano institucional e no } \\
\text { âmbito do curso? }\end{array}$ \\
\hline CPA - Comissão Própria de Avaliação & $\begin{array}{l}\text { De que forma os resultados da autoavaliação } \\
\text { servem de base para reordenação das ações } \\
\text { acadêmico-administrativas? }\end{array}$ \\
\hline
\end{tabular}

\section{RESULTADOS}

Como podemos observar a avaliação, como eixo do processo na gestão do PPI - Projeto Pedagógico Institucional, possibilita as instituições um diagnóstico das diferentes dimensões que envolvem a dinâmica curricular permitindo a interpretação da atuação dos sujeitos nos diferentes espaços, construindo uma consciência individual e coletiva sobre as ações em desenvolvimento e a necessidade de regulações constantes. Estas regulações sinalizam possíveis ações a serem realizadas no processo de construção do PPI- Projeto Pedagógico Institucional, constituindo-se em intervenções intencionais.

No caso da avaliação institucional, a implementação de ações de uma regulação mais interativa acontece quando a comunidade acadêmica se encontra para discutir os seus resultados e propor ações que contribuem com 0 planejamento institucional.

$\mathrm{Na}$ condição de avaliadoras in loco de Cursos e Credenciamento de IES, a experiência tem demonstrado que, quando no processo de autoavaliação a comunidade acadêmica é protagonista, ou seja, participa efetivamente da revisão da política curricular por meio do diagnóstico, da reflexão, análise e intervenção, existe de fato a compreensão dos sujeitos sobre o seu contexto institucional. Esta leitura evidencia-se quando buscamos a coerência entre os registros documentais e as evidências concretas que envolvem os sujeitos no PPI - Projeto Pedagógico 
Institucional das IES.

Quando nas entrevistas e relatos pedagógicos com os diferentes segmentos da comunidade acadêmica nos deparamos com registros caracterizados pela individualidade e pela improvisação, imediatamente constatamos a desarticulação entre as evidências analisadas nos documentos institucionais e o diálogo estabelecido. Este diagnóstico nos leva a refletir sobre a complexidade do campo avaliativo onde modos culturalmente estabelecidos implicam tensões inevitáveis. As dúvidas e inseguranças vivenciadas por docentes, discentes, gestores e equipe de especialistas, na condução do processo, geram conflitos, cujo movimento simultâneo tanto de resistências as mudanças como de abertura para outras alternativas, é confrontado com diferentes concepções e práticas que, por serem contraditórias, ora aproximam a comunidade acadêmica, ora limitam a sua participação.

A análise aqui empreendida nos mostra que os depoimentos revelam procedimentos e rotinas voltados tanto para um processo de avaliação regulatório quanto emancipatório, dependendo de como a IES tem conduzido o seu processo de autoavaliação. Para contextualizar esta realidade, utilizamos alguns questionamentos que são realizados nas entrevistas em loco.

Quando coordenadores de curso e gestores administrativos são questionados sobre "de que forma são operacionalizados e tratados os resultados do relatório emitido pela CPA", estes demonstram ênfase nos procedimentos e rotinas voltados para a constatação e registro das ações e não na tomada de decisão e retroalimentação do planejamento institucional.

Vemos que a cultura de uma avaliação de verificação, de classificação encontra-se presente na formação dos sujeitos, cujas dificuldades manifestadas, evidenciam a centralização no nível da certificação, constatação e retorno à comunidade acadêmica.

Este dado não foi percebido somente no envolvimento direto com os gestores, mas em momentos distintos e informais da rotina institucional com docentes e acadêmicos. Quando discentes e docentes são questionados sobre seu acesso às informações contidas no relatório de autoavaliação e sua participação nos debates e discussões sobre os resultados, evidencia-se a manifestação de insatisfação que é gerada pela ausência de providências quanto à tomada de decisão e possíveis encaminhamentos dos resultados da avaliação no que diz respeito a questões tanto administrativas quanto acadêmicas no planejamento institucional.

No entanto, cabe considerar que o contrário também é verdadeiro, IES que implementaram a necessidade de avaliação permanente e melhoria nos seus processos. Uma questão recorrente que contextualiza esta evidência é quando perguntados sobre a dinâmica de operacionalização das decisões da CPA e do NDE - Núcleo Docente Estruturante no cotidiano institucional e no âmbito do curso, observa-se nos relatos, intervenções significativas, como por exemplo, a participação do NDE na qualificação nos projetos pedagógicos de cursos, 0 programa de formação continuada dos professores, a qualificação dos planos de ensino docente, a reestruturação do programa de relacionamento com os egressos, a qualificação da metodologia da avaliação de aprendizagem, dentre outras. Esses dados são ratificados nas entrevistas com os membros da CPA, quando questionados de que forma os resultados da autoavaliação servem de base para reordenação das ações acadêmico-administrativas.

Nesta direção, vemos uma concepção e metodologia de avaliação 
emancipatória, cujos dados coletados, discutidos e interpretados pela comunidade acadêmica exigem a iniciação da fase da "ação" que, segundo Thiollent (1997, p. 58), "consiste, com base na investigação em curso, em difundir os resultados, definir objetivos alcançáveis por meio de ações concretas, apresentar propostas que poderão ser negociadas entre as partes interessadas".

Concordando com a afirmação de Sobrinho (2000), quando diz que avaliar é também um modo social de formar, fica evidente que a avaliação não se cumpre apenas como o desenvolvimento técnico de ações específicas, mas se integra ao conjunto dos processos de formação como cultura educativa.

Observa-se nos momentos de interação das avaliadoras com a comunidade acadêmica avaliada, que, mediante uma cultura emancipatória, as atitudes até então que ficavam centradas mais na constatação daquilo que se encontra instituído no PPI, desloca-se de uma ação instrumental para uma ação comunicacional, favorecendo a construção ética do discurso no grupo, dando sustentação para a reconstrução do currículo pelos próprios sujeitos.

Sobre esta questão, é pertinente citar Freire (1997), quando ele fala da relação do homem com a sua realidade, afirmando que fica difícil assumir um compromisso verdadeiro com a realidade, quando se tem desta realidade e dos sujeitos que dela fazem parte uma consciência ingênua. Quando o sujeito, que se diz comprometido, firma este compromisso mediante uma realidade dada, mecânica, estática, e o seu olhar perpassa por uma realidade parcial, como ele mesmo expressa, enclausurado em departamentos estanques, se não a enxerga e a sintoniza como totalidade, cujas partes interagem permanentemente, sua ação não consegue chegar, incidir sobre as partes desta realidade. É somente transformando esta totalidade que se consegue transformar as partes e não o contrário.

Neste sentido cabe salientar que a gestão do PPI - Projeto Pedagógico Institucional é realizada considerando não só o diagnóstico, os resultados da avaliação institucional, mas sobretudo, a tomada de decisão que implica na ação e intervenção dos sujeitos, mediante o diálogo, a leitura da instituição, a revisão de suas práticas curriculares pela seleção e ordenamento do currículo, a construção da autonomia nos diferentes níveis hierárquicos da instituição.

\section{CONSIDERAÇÕES FINAIS}

As constatações analisadas e refletidas a partir da experiência vivenciada pelas autoras nos processos de avaliações institucionais e de cursos em diversas instituições de ensino superior públicas e/ou privadas, de diferentes localidades e porte, possibilitaram as pesquisadoras um olhar reflexivo e crítico em relação ao processo de autoavaliação aplicado nas instituições pelas CPAs.

A partir de diferentes modelos de organização acadêmica foi possível identificar que a realização da autoavaliação em determinados contextos institucionais, ocorre meramente vinculada a uma exigência do SINAES, sendo assim, operadas de forma regulatória, sem envolvimento dos segmentos da comunidade acadêmica na proposição de ações que retroalimentem o PPI Planejamento Pedagógico Institucional. 
É perceptível por meio das entrevistas em loco constatar limitações presentes no PPI - Projeto Pedagógico Institucional em que, não ficam claros se os objetivos e as metas estão sendo alcançados, tendo em vista que, os resultados da avaliação institucional não auxiliam a mensurar o seu desempenho a partir de um padrão constituído coletivamente.

Por outro lado, observa-se em outras IES que, o processo de autoavaliação institucional deixou de ser uma atividade meramente burocrática no processo educativo e se transformou em componente curricular necessário, nos quais os resultados geram ações acadêmico-administrativas de melhoria contínua e para isso contam com a participação de todos os segmentos da comunidade acadêmica. Nesta perspectiva a avaliação e assumida como parte da cultura institucional, uma concepção de conhecimento enquanto processo e não como produto. A avaliação como instrumento democrático e emancipatório, cujos resultados propiciam conhecimento e ações que gerem crescimento e desenvolvimento institucional.

Podemos inferir que a avaliação, numa perspectiva emancipatória, encontra-se integrada ao processo pedagógico, vinculada a todos os aspectos que dizem respeito à vida da instituição e seu desenvolvimento, incluindo as atividades de ensino, pesquisa e extensão. Sendo assim, deve traduzir a evolução da identidade institucional, garimpando o que vem sendo realizado de bom por meio do aperfeiçoamento de projetos, tanto no âmbito institucional quanto no dos cursos de graduação, dando visibilidade às contribuições significativas para a comunidade. Assim, a avaliação estará voltada não somente para o desempenho das pessoas, mas igualmente para as condições objetivas de trabalho, ou seja, para o processo, uma vez que ela também é resultado deste (PIRES, 2005).

Portanto, concluímos este artigo, enfatizando a importância do fomento da cultura avaliativa como instrumento democrático e emancipatório, cujos resultados propiciam a atualização contínua do planejamento institucional, pois de nada adianta coletar dados, tabular, analisar e não transformá-los em conhecimento e ações que gerem crescimento e desenvolvimento institucional. 


\section{REFERÊNCIAS}

ABRAMOWICZ, Mere; LARA, Marcos Rodrigues de. Políticas Públicas de Avaliação. São Paulo: CRV, 2010.

AFONSO, Janela Almerindo. Avaliação educacional: regulação e emancipação: para uma sociologia das políticas avaliativas contemporâneas. São Paulo: Cortez, 2000.

CATANI, Afrânio Mendes; OLIVEIRA, João Ferreira de. As políticas de diversificação e diferenciação da educação superior no Brasil: Alterações no sistema e nas universidades públicas. In. SGUISSARDI, Valdemar (Org).

Educação superior: velhos e novos desafios. São Paulo: Xamã, 2000. p.63-81. CUNHA, Luiz Antônio. Educação e desenvolvimento social no Brasil. Rio de Janeiro: Francisco Alves, 2004.

FREIRE, Paulo. Pedagogia da autonomia: Saberes necessários à prática educativa. São Paulo: Paz e Terra, 1997.

PACHECO, José Augusto (Org.) Política de integração curricular. Portugal: Porto, 2000.

PIRES, Clarice. Referências para um Currículo Crítico-Emancipatório na Universidade:

Construindo o Projeto Educativo do Centro Universitário de Brusque. 2005. SOBRINHO, Dias José. Avaliação da educação superior. Petrópolis, RJ: Vozes, 2000.

THIOLLENT, Michel. Pesquisa-ação nas organizações. São Paulo: Atlas, 1997. 